\title{
Green polyurethane synthesis by emulsion technique: a magnetic composite for oil spill removal
}

\author{
Raphael Maria Dias da Costa1, Gabriela Hungerbühler', Thiago Saraiva1', Gabriel De Jong1, \\ Rafael Silva Moraes ${ }^{1}$, Evandro Gonçalves Furtado², Fabrício Machado Silva ${ }^{3}$, \\ Geiza Esperandio de Oliveira ${ }^{4}$, Luciana Spinelli Ferreira ${ }^{1,5}$ and Fernando Gomes de Souza Junior ${ }^{1,4 *}$
}

'Laboratório de Biopolímeros e Sensores - LaBioS, Instituto de Macromoléculas - IMA, Universidade Federal do Rio de Janeiro - UFRJ, Rio de Janeiro, RJ, Brazil

${ }^{2}$ Alfa Rio Química Ltda., Duque de Caxias, RJ, Brazil

${ }^{3}$ Instituto de Química - IQ, Universidade de Brasília - UnB, Brasilia, DF, Brazil

${ }^{4}$ Programa de Engenharia Civil - PEC, Instituto Alberto Luiz Coimbra de Pós-graduação e Pesquisa de Engenharia - COPPE, Universidade Federal do Rio de Janeiro - UFRJ, Rio de Janeiro, RJ, Brazil

${ }^{5}$ Programa de Engenharia da Nanotecnologia - PENt, Instituto Alberto Luiz Coimbra de Pós-graduação e Pesquisa em Engenharia - COPPE, Universidade Federal do Rio de Janeiro - UFRJ, Rio de Janeiro, RJ, Brazil

*fgsj@ufrj.br

\begin{abstract}
After the consolidation of the Brazilian biodiesel industry, issues related to the final destination of the glycerin, the by-product from the biodiesel industrial process, drawing the attention of several researchers. There are several uses to this byproduct. Among them, the obtaining of polymers, such as polyurethane (PU), are very encouraged since the glycerin ca be used, as well as the castor oil, in the replacement of petrochemical polyols. The aim of this work was to propose a new route for the obtainment of a petroleum sorbent based on polyurethane resin from glycerin and castor oil, through the emulsion technique. In addition, maghemite $\left(\gamma-\mathrm{Fe}_{2} \mathrm{O}_{3}\right)$ was mixed to the polymer matrix, producing a magnetic composite, able to make easier the oil cleanup process. The products synthesized were characterized by Fourier transform infrared spectroscopy, X-ray diffraction, simultaneous Thermogravimetry (TGA) and Differential scanning calorimetry (DSC), Optical microscopy, Scanning electron microscopy (SEM). In addition, magnetic force and oil removal capability tests were also performed. The magnetic material was used to remove oil from water, exhibited a good oil removal capability. In a typical test, $1 \mathrm{~g}$ of the composite containing $5 \mathrm{wt} \%$ of maghemite was able to remove $10 \mathrm{~g}$ of oil from water.
\end{abstract}

Keywords: green polyurethanes, glycerin, castor oil, maghemite, magnetic composites.

\section{Introduction}

The biodiesel consists of an alkylester of fatty acids, obtained by the transesterification of vegetable oils or animal fats, using a small chain alcohol, such as methanol or ethanol. Aiming the replacement of part of the fossil fuels employed as an energy source, the production of Brazilian biodiesel as alternative fuel has been increased during the last years $^{[1]}$. The Brazilian law $n^{0} 11.097$ / 2005 determined the increasingly addition of biodiesel to diesel. From the initial amount of $2 \%$, nowadays $7 \%$ of biodiesel is added to the diesel $^{[2]}$. So, the growing using of the biodiesel is responsible for the surplus production of glycerol (each $100 \mathrm{~kg}$ of the biodiesel can generate $10 \mathrm{~kg}$ of glycerol). Therefore, as long as the usage of biodiesel as alternative fuel has been encouraged by Brazilian Government, innovative uses for the glycerin source must be pursued ${ }^{[3]}$.

In this context, the glycerin can be employed for the production of resins, such as polyurethanes. The polyurethanes (PU) are one of the most important polymeric materials, showing different characteristics and applications ${ }^{[4-6]}$. Among the variety of applications, PUs can be employed as oil spill cleanup agents from aqueous systems ${ }^{[7-9]}$, which is a major concern since petroleum use always involves a

considerable risk of oil spillage ${ }^{[10,11]}$ that could occur during its transportation and storage ${ }^{[12]}$. Thus, in a previous work from our research group, magnetic foams were prepared with the insertion of maghemite nanoparticles into a polymer matrix, aiming to make the removal of the polymer material containing petroleum from the water surface easier ${ }^{[9]}$. These foams were prepared from renewable feedstock, as castor oil and glycerin (byproduct from the biodiesel industry). However, this material was obtained by a bulk polymerization process, in which there are relevant operational issues. Among them, the use of higher temperatures and the need of additional steps, such as the milling of the obtained polymer, make the final process less competitive from the industrial point of view.

Therefore, the main goal of this work was the preparation of a magnetic oil sorbent, by emulsion polymerization. Presented material is a polyurethane resin obtained from renewable feedstock in the presence of maghemite nanoparticles ${ }^{[13]}$. Emulsion technique allows to perform the reaction in lower temperatures and reduced viscosity of the reaction medium in comparison to the bulk technique used previously ${ }^{[9]}$. In addition, the composite is obtained as very small particles 
at the end of polymerization. The material was used in oil spill cleanup tests and results shown that each gram of PU is able to remove around ten grams of oil. This result is very encouraging since each gram of the previous material, milled after the by bulk polymerization, was able to remove four grams of the petroleum from the water.

\section{Experimental Part}

\subsection{Materials}

Glycerin and sodium lauryl ether sulfate $\left(\mathrm{C}_{12} \mathrm{H}_{25} \mathrm{NaO}_{4} \mathrm{~S}\right)$ were purchased from Vetec (Rio de Janeiro, Brazil). Dodecylbenzenesulfonic acid (DBSA) was purchased from Solquim LTDA (Brazil). Castor oil was kindly donated by Petrobras, with density in the range of 0.954-0.965 (@2 $25^{\circ} \mathrm{C}$ ). Toluene diisocyanate (TDI, $\mathrm{C}_{9} \mathrm{H}_{6} \mathrm{O}_{2} \mathrm{~N}_{2}$ ) was purchased from Bayer (Rio de Janeiro, Brazil). These reagents were used as received, without further purification.

\subsection{Preparation of the emulsion}

Before the polymerization, the emulsion was prepared following the methodology described in the literature ${ }^{[14]}$. In a typical procedure, a solution containing $0.5 \mathrm{~g}$ of DBSA into 1 liter of distilled water was previously prepared, and employed as continuous phase. Castor oil, glycerin and sodium lauryl ether sulfate (SLES) were dispersed in the aqueous solution, by using a homogenizer Polytron (PT 3100 D), at 10,000 rpm for 10 minutes, using different amounts of monomers, surfactants and catalyst, which are described in the section 2.4 .

\subsection{Synthesis of maghemite}

As described in previous works ${ }^{[9,15-25]}$, our group is interested in the maghemite synthesis and we used similar approaches to obtain this nano material. Specifically in the present work, aqueous solutions of hydrochloric acid (2 M), ferric chloride (2 M), and sodium sulfite (1 M) were prepared. Into a beaker, under continuous agitation, $30 \mathrm{~mL}$ of the ferric chloride solution and $30 \mathrm{~mL}$ of deionized water were added. Soon afterwards, $20 \mathrm{~mL}$ of the sodium sulfite solution was added to the beaker, still under continuous agitation. The reaction product was precipitated by slowly adding $51 \mathrm{~mL}$ of concentrated ammonium hydroxide into the beaker under continuous agitation. The medium was poured after $30 \mathrm{~min}$. The obtained nanoparticles were washed several times using distilled water and finally dried to constant weight at $60^{\circ} \mathrm{C}$ in an oven. After that, sample was heating at $250{ }^{\circ} \mathrm{C}$ for $1 \mathrm{~h}$.

\subsection{Synthesis of polymer and composite}

Soon afterwards the emulsion preparation, the polymerization took place at $70{ }^{\circ} \mathrm{C}$ using TDI $(0.309 \mathrm{~mol})$, glycerin $(0.204 \mathrm{~mol})$, castor oil $(0.002 \mathrm{~mol})$ and surfactant (0.0069 mol). Synthesis was carried out under continuous and stirring by a mechanical stirrer Fisatom (model 713D), at $800 \mathrm{rpm}$; and heated by a magnetic stirrer with heating from IKA (model C-MAG HS7) with a thermocouple attached. During stirring, TDI was added into the reaction medium. The product was precipitated in an excess of ethanol, and filtered. The composite was prepared following the same steps, except for the inclusion of $5 \mathrm{wt} \%$ of maghemite, which was performed by the dispersion of the filler in the medium containing the emulsion also under mechanical stirring.

\subsection{Characterization}

Polymer, maghemite and composite were analyzed in a Fourier transform infrared with the attenuation reflectance accessory (FTIR-ATR), from Nicolet model iN10. The used range was from 4000 to $600 \mathrm{~cm}^{-1}$, with 20 scans accumulated in a resolution of $4 \mathrm{~cm}^{-1}$. Maghemite and composite were characterized by X-ray diffraction (XRD), on a Rigaku-ULTIMA IV X-ray diffractometer, in the angular range $2 \theta$ from $2^{\circ}$ to $80^{\circ}$, using $\mathrm{CuK} \alpha$ radiation ( $\mathrm{k}=1.5418 \AA, 30 \mathrm{kV}$ and $15 \mathrm{~mA})$. Optical microscopy was performed in a Bel Photonics microscope, aiming the calculation of the particles diameter. Magnetic force test of maghemite/composite was performed following the procedure established in our laboratory ${ }^{[22]}$. Simultaneous TGA-DSC analysis were performed using a PerkinElmer STA-6000 in the temperature range between $28-670{ }^{\circ} \mathrm{C}$ in $20 \mathrm{~mL} / \mathrm{min}$ flow of nitrogen and heating rate of $10^{\circ} \mathrm{C} / \mathrm{min}$. The Scanning Electron Microscopy was performed using a JEOL JSM-5610 LV with acceleration voltage of $15 \mathrm{kV}$. The cure degree was performed using a sample, previously weighed, inside a Soxhlet extractor in a filter paper package. The used solvent during the extraction process was an equivolumetric mixture of toluene, heptane and cyclohexane at $250{ }^{\circ} \mathrm{C}$. Then, the samples were dried and weighed again to determine the weight lost and, consequently, the cure degree. For the oil removal test, in $300 \mathrm{~mL}$ beaker, $2 \mathrm{~g}$ of petroleum were spilt on a $150 \mathrm{~mL}$ saline water solution (55000 ppm, containing $\mathrm{NaCl}$ and $\mathrm{CaCl}_{2}$, in a 10:1 rate). Then, a known amount of the magnetic resin was poured into the oily system. After 5 minutes, the oil and composite were magnetically removed, and the mass of the oil residue could be determined by gravimetry ${ }^{[26]}$.

\section{Results and Discussion}

Figure 1 shows the samples FTIR spectra of the resin, maghemite and composite filled with $5 \mathrm{wt} \%$ of maghemite. The FTIR spectrum of the resin is presented in the Figure 1a. Among its characteristic bands it is possible to see a wide one related to $\mathrm{O}-\mathrm{H}$ stretching of the hydroxyl group, which takes place around $3300 \mathrm{~cm}^{-1}$. The profile of this band is associated with the hydrogen bond that these compounds are able to form. The intense characteristic peak observed at $2272 \mathrm{~cm}^{-1}$ is related to the stretching of the bands $\mathrm{N}=\mathrm{C}=\mathrm{O}$ from isocyanate groups. The characteristic band located around $1650 \mathrm{~cm}^{-1}$ is $\mathrm{C}=\mathrm{O}$ axial deformation from carbonyl group. While the vibration of $\mathrm{C}-\mathrm{N}$ band takes place at $1540 \mathrm{~cm}^{-1}$. The presence of the remaining cyanate group indicates reactive sites which can allow further modifications in the resin surface. In the FTIR spectrum of the maghemite, presented in the Figure 1b, the main characteristic bands appears around (i) $3450 \mathrm{~cm}^{-1}$, associated with the $\mathrm{Fe}-\mathrm{OH}$ and $\mathrm{O}-\mathrm{H}$ conjugated bands, and at (ii) 634 and $584 \mathrm{~cm}^{-1}$, related to stretching of the band $\mathrm{Fe}-\mathrm{O}$, from the phases $\varepsilon-\mathrm{Fe}_{2} \mathrm{O}_{3} \mathrm{e}$ $\alpha-\mathrm{Fe}_{2} \mathrm{O}_{3}$, respectively ${ }^{[27]}$. 
In turn, the spectra of the composite did not present any significant difference (Figure 1c), when compared to the matrix, which can indicate the absence of significant chemical interactions between the matrix and the filler, due to the small amount of the latter.

Pure resin presents only a broad hump around $23^{\circ}$, which is related to the amorphous nature of this macromolecular material. The X-ray diffratogram of pure maghemite presents peaks at $30.29^{\circ}, 35.39^{\circ}, 42.91^{\circ}, 52.97^{\circ}, 57.36^{\circ}$ and $62.86^{\circ}$, corresponding to (220), (311), (440), (400), (511) and (440) crystalline plane from an orthorhombic crystal system. Crystallite size was calculated in accordance with Scherer's Equation 1, using the sharpest peak placed at $2 \theta$ equal to $35.61^{\circ}$, related to the (331) plane of the maghemite (Figure 2).

$$
C s=K \lambda /(\beta \cos \theta)
$$

In Equation 1, Cs is the crystallite size, $\lambda$ the wavelength,

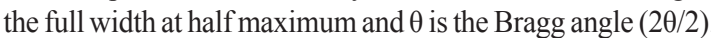

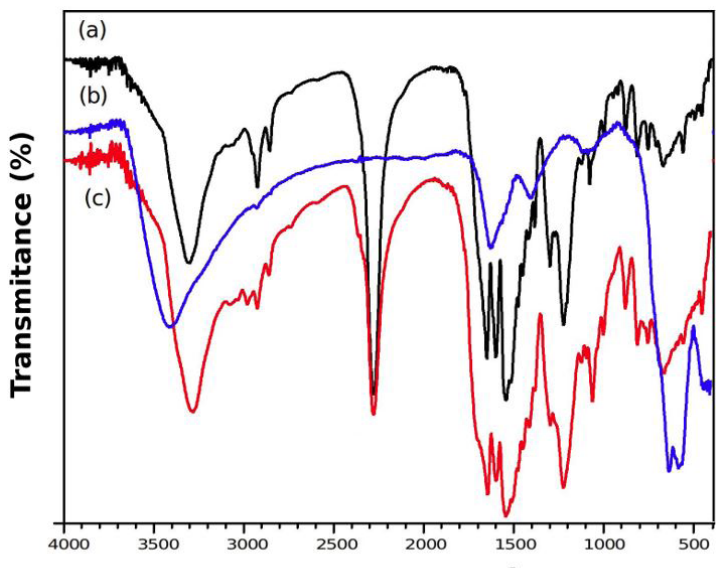

Wavenumber $\left(\mathrm{cm}^{-1}\right)$

Figure 1. FTIR spectra of PU resin (a), maghemite (b) and composite filled with $5 \mathrm{wt} \%$ of the maghemite (c).

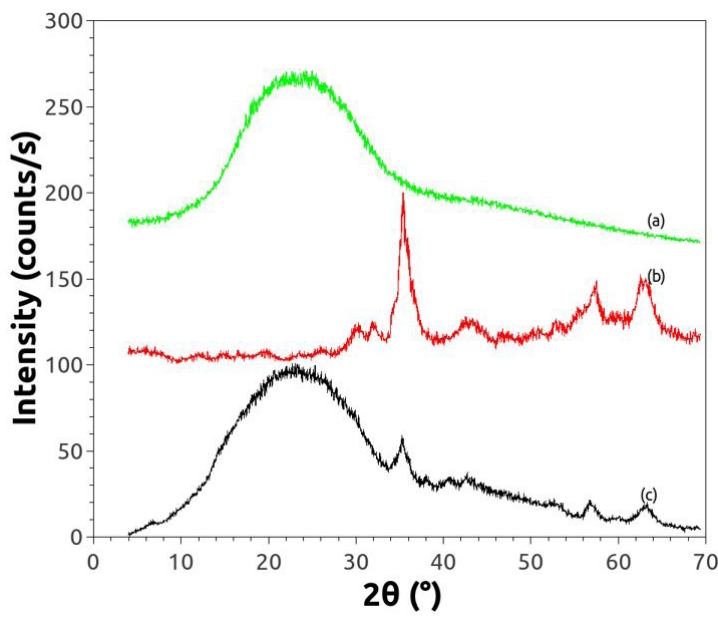

Figure 2. XRD of PU resin (a), maghemite (b) and composite filled with $5 \mathrm{wt} \%$ of the maghemite (c).
From this calculation, the crystallite size obtained for pure maghemite was equal to $6.5 \pm 0.5 \mathrm{~nm}$, while in the composite, its value was equal to $7.0 \pm 0.6$, which guarantees the nanometric size of maghemite particles inside the composite without the formation of agglomerated material.

Figure 3 shows the optical micrography and the probability density function of resin and composite particles. Obtained results, with $95 \%$ of confidence, allow inferring that the diameters of the polymer particles ranges between 5.20 and $21.02 \mu \mathrm{m}$. In addition, the most probable observed value is equal to $14.06 \mu \mathrm{m}$. In turn, the diameters of the composite particles ranges between 3.84 and $23.31 \mu \mathrm{m}$ and the most probable observed value is equal to $13.70 \mu \mathrm{m}$.

The size of the samples, in both cases, was equal to 43 counts. Obtained results allow us to infer that the size of the particles remains statistically the same after the preparation of the composite material.

The results from the magnetic force test under the influence of different magnetic fields are shown in the Figure 4.

There is an increase in the magnetic force when the magnetic field is increased, proving the presence of magnetic properties. In addition, magnetic force at maximum magnetic field (equal to 780 Gauss) of the pure maghemite and composite was equal to $824.8 \pm 0.02 \mathrm{mN} / \mathrm{g}$ and $735.9 \pm 0.001 \mathrm{mN} / \mathrm{g}$, respectively. The value for the composite is slightly lower than the one for the pure maghemite, due to the small amount of the filler in the polymer matrix (equal to $5 \mathrm{wt} \%$ ).

Figure 5 shows the simultaneous TGA-DSC analysis of the tested materials. Composite presents a small weight loss before $100{ }^{\circ} \mathrm{C}$, which is related to the residual water. The magnetic composite remains thermally stable before $227^{\circ} \mathrm{C}$, while the petroleum and the resin impregnated of petroleum are stable before $133{ }^{\circ} \mathrm{C}$ and $224^{\circ} \mathrm{C}$, respectively. From $135^{\circ} \mathrm{C}$ to $515^{\circ} \mathrm{C}$, petroleum lost $95 \%$ of its weight, thus this petroleum is mainly compounded by heavy fractions ${ }^{[28]}$. In the $280-380{ }^{\circ} \mathrm{C}$ range petroleum presented the smallest weight loss, equal to $25.6 \mathrm{wt} \%$ while composite impregnated of petroleum and composite presented $39.5 \mathrm{wt} \%$ and $55.3 \mathrm{wt} \%$, respectively. In spite of presented weight loss, petroleum did not present an increase of the weight loss rate in this range while composite and composite impregnated of petroleum did. Something similar took place in DSC results. Thus, the observed enthalpic phenomenon is mainly related to the decomposition of composite and the associated enthalpy allow us to infer that along decomposition, the studied composite absorbed $346 \mathrm{~J} / \mathrm{g}$ while composite impregnated of petroleum only $168 \mathrm{~J} / \mathrm{g}$. This difference is due to the crude oil presence, which did not absorb heat in this temperature range. On the other hand, the second weight loss event, from 410 to $530{ }^{\circ} \mathrm{C}$, is mainly related to the considerable presence of lubricating $\left(\mathrm{C}_{26}-\mathrm{C}_{38}\right.$ and 4-10 rings per molecule $\left.{ }^{[29]}\right)$ and vacuum gas oil (mainly composed by high paraffins ${ }^{[30]}$ ) inside tested petroleum. TGA results between 410 and $530^{\circ} \mathrm{C}$ allowed inferring that composite, composite impregnated of petroleum and petroleum presented weight loss equal to $6.8 w t \%, 22.9 w t \%$ and $41.8 w t \%$, respectively. In turn, DSC results showed that petroleum and composite impregnated of petroleum presented considerable endothermic events.

The enthalpy of composite, composite impregnated of petroleum and petroleum, in the same temperature range, 

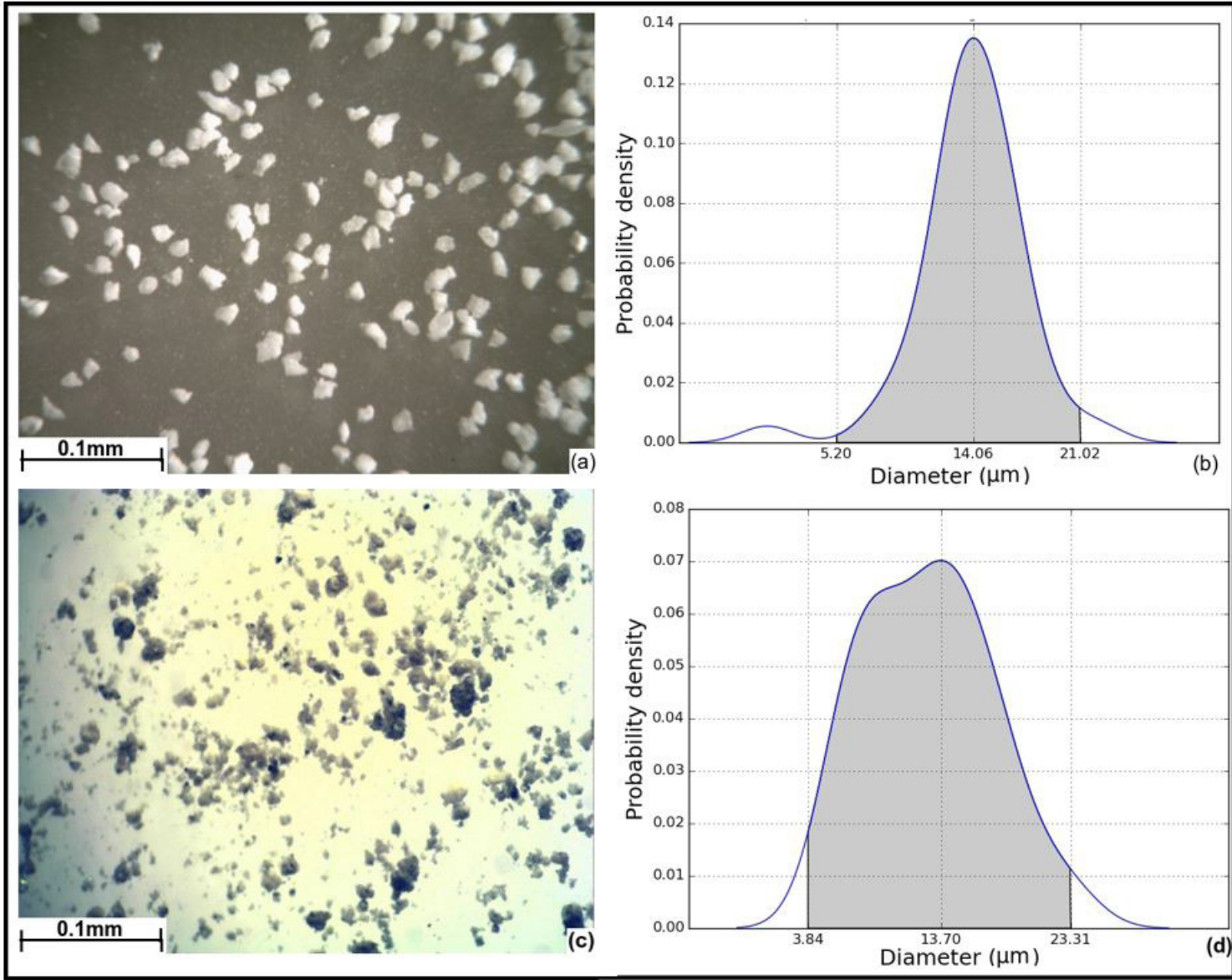

Figure 3. Optical microscopy and probability density function of the diameter of the resin (a \& b) and composite (c \& d).

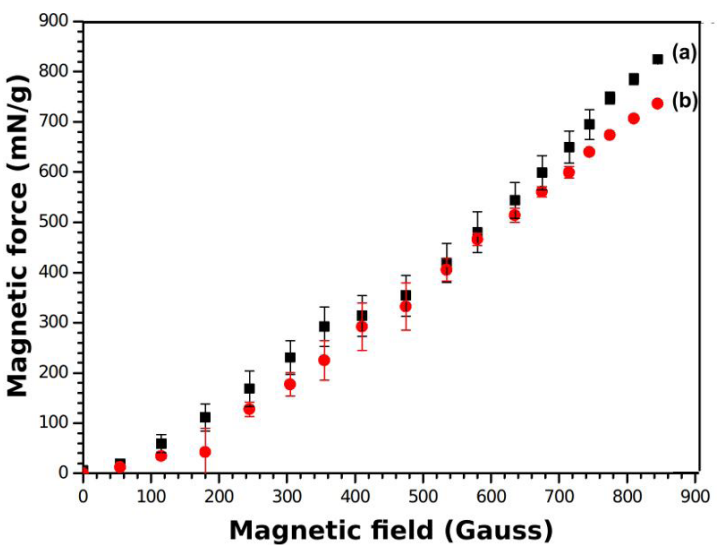

Figure 4. Magnetic force test of the pure maghemite (a) and the composite containing $5 \mathrm{wt} \%$ of the maghemite (b).

were equal to $9.3 \mathrm{~J} / \mathrm{g}, 21.3 \mathrm{~J} / \mathrm{g}$ and $84.2 \mathrm{~J} / \mathrm{g}$, respectively. Thus, considering that enthalpy of composite and petroleum are equal to $0 \%$ and $100 \%$ of petroleum in the samples, the amount of remain heavy fractions on the surface of the composite can be estimated by interpolation. Therefore, calculations lead to the conclusion that there was at least $16 \%$ of petroleum absorbed on the surface of the composite. This result is in agreement with the SEM one, showed in Figure 6, which

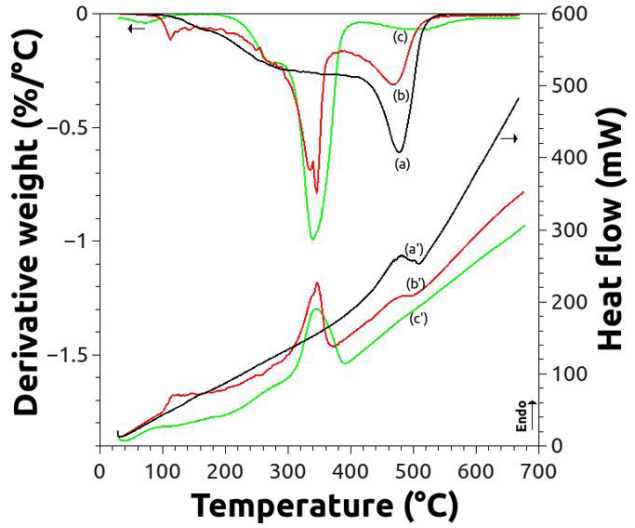

Figure 5. Simultaneous TGA-DSC analysis of petroleum (a \& a') composite impregnated of petroleum ( $b$ \& b') and composite (c \& c').

allowed to see that studied material presented a porous surface, able to absorb the petroleum, making easier the oil removal from the water. Figure 6 also showed the SEM of the pure maghemite. The particles are agglomerated due to the drying process, which is indispensable to the obtaining of the micrography in low vacuum. In spite this agglomeration, particles presented an average diameter, calculated using the image $\mathrm{\circledR}$ software, equal to $(108 \pm 17) \mathrm{nm}$. This is an 

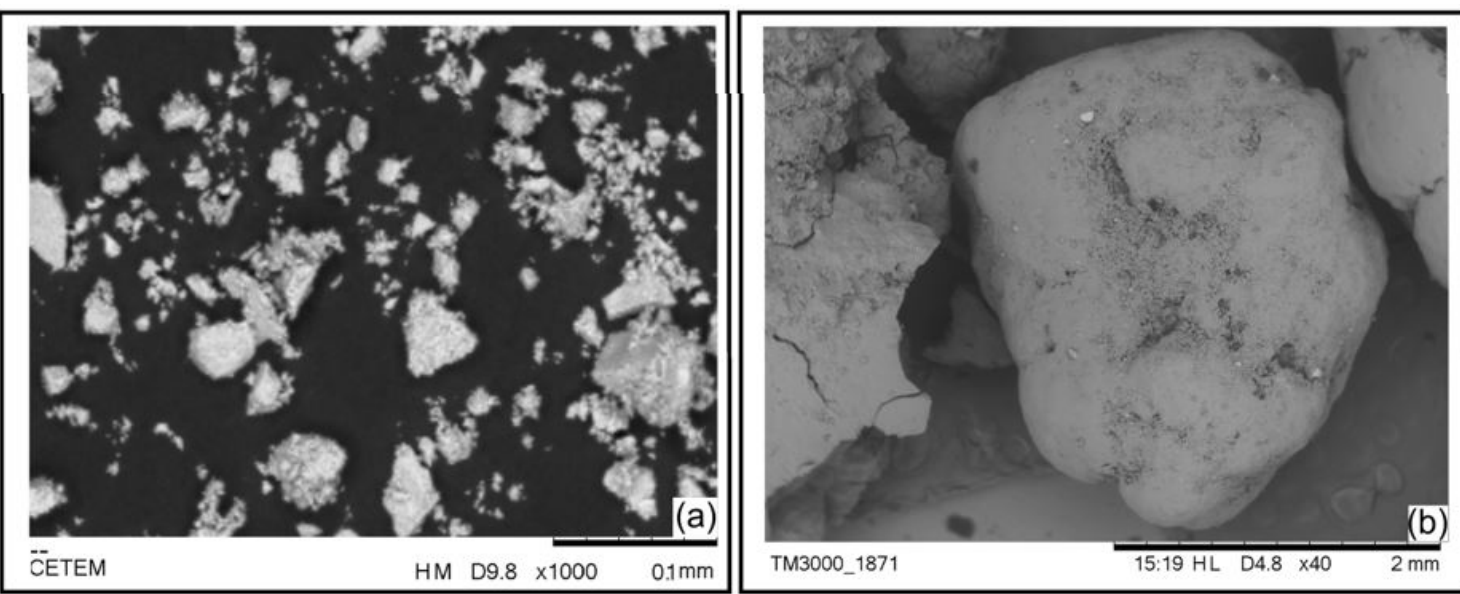

Figure 6. Scanning electron microscope image of the maghemite (a) and composite (b).

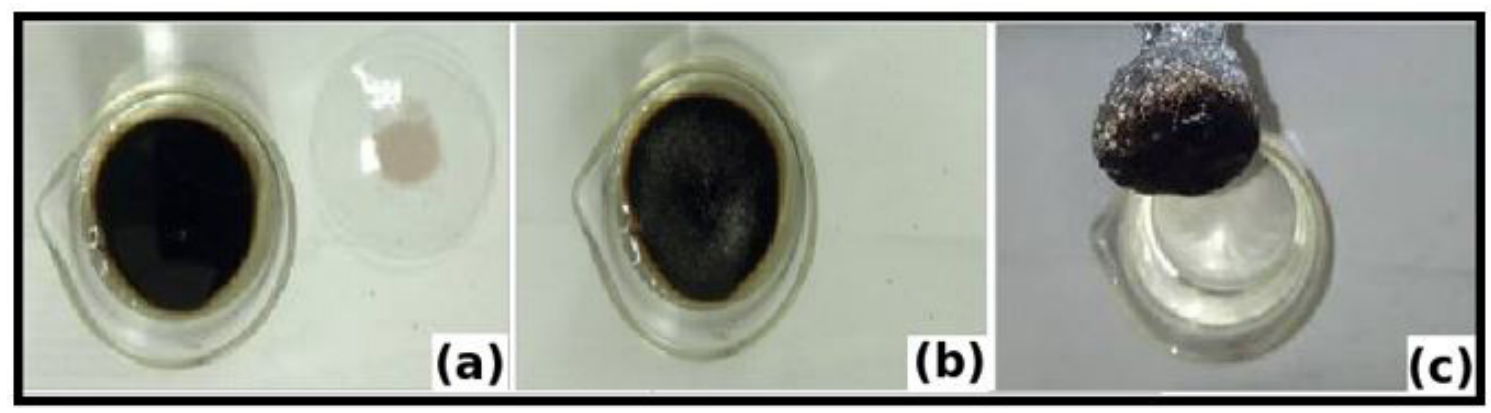

Figure 7. Oil removal from water using a magnetic composite: water with oil spilled (a), oil after the addition of the hybrid material (b) and oil and resin removed using a magnet (c).

interesting value, since allows the easy dispersion of these small magnetic particles within the emulsion phase.

The insertion of maghemite into the polymer matrix aims to make easier the cleanup process, removing both petroleum and resin from the aqueous system. The oil removal capability tests, showed in Figure 7, were performed according to the analytical procedure established in our laboratory ${ }^{[18]}$.

Before oil removal tests, the prepared resin was dispersed in water, where it was kept for five minutes. After this time, the resin was collected using a nylon sieve. Obtained results showed that $1.00 \mathrm{~g}$ of the resin absorbs only $0.25 \mathrm{~g}$ of water, demonstrating the hydrophobic property of the material. Oil removal tests using the presented magnetic composite, prepared here by emulsion, showed that each gram of the composite is able to remove $(10.0 \pm 0.2) \mathrm{g}$ of petroleum from the water. For comparative purpose, in a previous work ${ }^{[9]}$ our group produced a magnetic PU based on castor oil, toluene diisocyanate and water by a bulk polymerization. Each gram of this material was able to remove $(4.1 \pm 0.1) \mathrm{g}$ of petroleum from the water. Other example is the peat, a common raw material, which is able to sorb around $3.9 \mathrm{~g}$ of petroleum when exposed to this contaminant for $5 \mathrm{~min}^{[31]}$, however, without the magnetic removal capability, which speeds up the oil spill cleanup process. Thus, the material presented here has larger oil removal capability, being cheaper (due to the use of glycerin) and easier to prepare than the ours previous one. In addition, tested materials presented an average cure degree equal to $(99.3 \pm 0.2) \%$, which means that, after an oil extraction by solvents, the sorbers can be reused, as proved by three additional tests, which showed that oil removal capability remained the same. The advantages of the preparation by emulsion are very encouraging, since the material can be easily prepared and it is obtained in the granular form, avoiding the milling process. Therefore, presented material is promising to the cleanup process and environmental recovery.

\section{Conclusions}

Previous experiments have shown the viability of obtaining polyurethane from castor oil and glycerin through an emulsion technique. The employment of alternative feedstock is a route for the synthesis of green resins. The emulsion polymerization was able to produce crude oil absorbers, with a high cure degree. This is a technological advantage, since it can promote the reusing of the absorber material, as well as the crude oil recovery. The addition of magnetic nanoparticles into the polymer matrix allowed the production of a magnetic composite, which possesses a good magnetic force. Obtained magnetic force constitutes other technological advantage, since the use of magnetic tools make easier the cleanup process. The oil removal capability of the material is equal to $(10.0 \pm 0.2) \mathrm{g}$ of petroleum per gram of material. This is an improvement in 
the oil removal capability of this material, which allows its use in oil spill cleanup processes. Therefore, the prepared material contributes to the environment encouraging nobler uses to some available renewable resources.

\section{Acknowledgements}

The authors thank to Conselho Nacional de Desenvolvimento Científico e Tecnológico (CNPq-474940/2012-8 and 550030/2013-1), Coordenação de Aperfeiçoamento de Pessoal de Nível Superior (CAPES and CAPES-NANOBIOTEC), Financiadora de Estudos e Projetos (FINEP PRESAL Ref.1889/10) and Fundação Carlos Chagas Filho de Amparo à Pesquisa do Estado do Rio de Janeiro (FAPERJ) for the financial support and scholarships.

\section{References}

1. Pinto, A. C., Guarieiro, L. L. N., Rezende, M. J. C., Ribeiro, N. M., Torres, E. A., Lopes, W. A., Pereira, P., \& Andrade, J. (2005). Biodiesel: an overview. Journal of the Brazilian Chemical Society, 16(6B), 1313-1330. http://dx.doi.org/10.1590/ S0103-50532005000800003.

2. Padula, A. D., Santos, M. S., Ferreira, L., \& Borenstein, D. (2012). The emergence of the biodiesel industry in Brazil: current figures and future prospects. Energy Policy, 44, 395405. http://dx.doi.org/10.1016/j.enpol.2012.02.003.

3. Leoneti, A. B., Aragão-Leoneti, V., \& Oliveira, S. V. W. B. (2012). Glycerol as a by-product of biodiesel production in Brazil: alternatives for the use of unrefined glycerol. Renewable Energy, 45, 138-145. http://dx.doi.org/10.1016/j. renene.2012.02.032.

4. Raquez, J.-M., Deléglise, M., Lacrampe, M.-F., \& Krawczak, P. (2010). Thermosetting (bio)materials derived from renewable resources: a critical review. Progress in Polymer Science, 35(4), 487-509. http://dx.doi.org/10.1016/j.progpolymsci.2010.01.001.

5. Lligadas, G., Ronda, J. C., Galià, M., \& Cádiz, V. (2010). Oleic and undecylenic acids as renewable feedstocks in the synthesis of polyols and polyurethanes. Polymers, 2(4), 440-453. http:// dx.doi.org/10.3390/polym2040440.

6. Manjula, K., Satheesh Kumar, M., Soare, B. G., Picciani, P., \& Siddaramaiah, (2010). Biobased chain extended polyurethane and its composites with silk fiber. Polymer Engineering and Science, 50(4), 851-856. http://dx.doi.org/10.1002/pen.21604.

7. Yang, J. S., Cho, S. M., Kim, B. K., \& Narkis, M. (2005). Structured polyurethanes for oil uptake. Journal of Applied Polymer Science, 98(5), 2080-2087. http://dx.doi.org/10.1002/ app.22419.

8. Li, H., Liu, L., \& Yang, F. (2012). Hydrophobic modification of polyurethane foam for oil spill cleanup. Marine Pollution Bulletin, 64(8), 1648-1653. PMid:22749062. http://dx.doi. org/10.1016/j.marpolbul.2012.05.039.

9. Lopes, M. C., Souza, F. G., Jr., \& Oliveira, G. E. (2010). Espumados magnetizáveis úteis em processos de recuperação ambiental. Polímeros: Ciência e Tecnologia, 20(5), 359-365. http://dx.doi.org/10.1590/S0104-14282010005000054.

10. Peng, L., Yuan, S., Yan, G., Yu, P., \& Luo, Y. (2014). Hydrophobic sponge for spilled oil absorption. Journal of Applied Polymer Science, 131(20), 1. http://dx.doi.org/10.1002/app.40886.

11. Li, H., Wu, W., Bubakir, M. M., Chen, H., Zhong, X., Liu, Z., Ding, Y., \& Yang, W. (2014). Polypropylene fibers fabricated via a needleless melt-electrospinning device for marine oilspill cleanup. Journal of Applied Polymer Science, 131(7), 1. http://dx.doi.org/10.1002/app.40080.
12. Annunciado, T. R., Sydenstricker, T. H. D., \& Amico, S. C. (2005). Experimental investigation of various vegetable fibers as sorbent materials for oil spills. Marine Pollution Bulletin, 50(11), 1340-1346. PMid:15946707. http://dx.doi.org/10.1016/j. marpolbul.2005.04.043.

13. Philippova, O., Barabanova, A., Molchanov, V., \& Khokhlov, A. (2011). Magnetic polymer beads: recent trends and developments in synthetic design and applications. European Polymer Journal, 47(4), 542-559. http://dx.doi.org/10.1016/j. eurpolymj.2010.11.006.

14. Zanetti-Ramos, B. G., Lemos-Senna, E., Soldi, V., Borsali, R., Cloutet, E., \& Cramail, H. (2006). Polyurethane nanoparticles from a natural polyol via miniemulsion technique. Polymer, 47(24), 8080-8087. http://dx.doi.org/10.1016/j.polymer.2006.09.057.

15. Costa, R. C., \& Souza, F. G. (2014). Preparo de nanocompósitos maghemita e polianilina assistido por ultrassom. Polímeros: Ciência e Tecnologia, 24(2), 243-249. http://dx.doi.org/10.4322/ polimeros.2014.035.

16. de Souza, F., Marins, J., Pinto, J., de Oliveira, G., Rodrigues, C., \& Lima, L. (2010). Magnetic field sensor based on a maghemite/polyaniline hybrid material. Journal of Materials Science, 45(18), 5012-5021. http://dx.doi.org/10.1007/s10853010-4321-y.

17. Elias, E., Costa, R., Marques, F., Oliveira, G., Guo, Q., Thomas, S., \& Souza, F. G., Jr. (2015). Oil-spill cleanup: the influence of acetylated curaua fibers on the oil-removal capability of magnetic composites. Journal of Applied Polymer Science, 132(13), 1. PMid:25866416. http://dx.doi.org/10.1002/ app. 41732 .

18. Gomes de Souza, F., Jr., Marins, J. A., Rodrigues, C. H. M., \& Pinto, J. C. (2010). A magnetic composite for cleaning of oil spills on water. Macromolecular Materials and Engineering, 295(10), 942-948. http://dx.doi.org/10.1002/mame.201000090.

19. Oliveira, G. E., Clarindo, J. E. S., Santo, K. S. E., \& Souza, F. G., Jr. (2013). Chemical modification of cobalt ferrite nanoparticles with possible application as asphaltene flocculant agent. Materials Research, 16(3), 668-671. http://dx.doi. org/10.1590/S1516-14392013005000048.

20. Pereira, E. D., Souza, F. G., Jr., Santana, C. I., Soares, D. Q., Lemos, A. S., \& Menezes, L. R. (2013). Influence of magnetic field on the dissolution profile of cotrimoxazole inserted into poly(lactic acid-co-glycolic acid) and maghemite nanocomposites. Polymer Engineering and Science, 53(11), 2308-2317. http://dx.doi.org/10.1002/pen.23606.

21. Neves, J. S., Souza, F. G., Jr., Suarez, P. A. Z., Umpierre, A. P., \& Machado, F. (2011). In situ production of polystyrene magnetic nanocomposites through a batch suspension polymerization process. Macromolecular Materials and Engineering, 296(12), 1107-1118. http://dx.doi.org/10.1002/mame.201100050.

22. Souza, F. G., Jr., Ferreira, A. C., Varela, A., Oliveira, G. E., Machado, F., Pereira, E. D., Fernandes, E., Pinto, J. C., \& Nele, M. (2013). Methodology for determination of magnetic force of polymeric nanocomposites. Polymer Testing, 32(8), 14661471. http://dx.doi.org/10.1016/j.polymertesting.2013.09.018.

23. Varela, A., Oliveira, G., Souza, F. G., Jr., Rodrigues, C. H. M., \& Costa, M. A. S. (2013). New petroleum absorbers based on cardanol-furfuraldehyde magnetic nanocomposites. Polymer Engineering and Science, 53(1), 44-51. http://dx.doi. org/10.1002/pen.23229.

24. Grance, E. G. O., Souza, F. G., Jr., Varela, A., Pereira, E. D., Oliveira, G. E., \& Rodrigues, C. H. M. (2012). New petroleum absorbers based on lignin $\square \mathrm{CNSL} \square$ formol magnetic nanocomposites. Journal of Applied Polymer Science, 126(S1), E305-E312. http://dx.doi.org/10.1002/app.36998.

25. Pereira, E. D., Souza, F. G., Jr., Pinto, J. C. C. S., Cerruti, R., \& Santana, C. (2014). Synthesis, characterization and drug 
delivery profile of magnetic PLGA-PEG-PLGA/maghemite nanocomposite. Macromolecular Symposia, 343(1), 18-25. http://dx.doi.org/10.1002/masy.201300168.

26. Ferreira, L. P., Moreira, A. N., Delazare, T., Oliveira, G. E., \& Souza, F. G., Jr. (2012). Petroleum absorbers based on CNSL, furfural and lignin: the effect of the chemical similarity on the interactions among petroleum and bioresins. Macromolecular Symposia, 319(1), 210-221. http://dx.doi.org/10.1002/ masy.201100145.

27. Hu, L., Hach, D., Chaumont, D., Brachais, C.-H., \& Couvercelle, J.-P. (2008). One step grafting of monomethoxy poly(ethylene glycol) during synthesis of maghemite nanoparticles in aqueous medium. Colloids and Surfaces. A, Physicochemical and Engineering Aspects, 330(1), 1-7. http://dx.doi.org/10.1016/j. colsurfa.2008.07.044.

28. Speight, J. G., \& Ozum, B. (2001). Petroleum refining processes. Boca Raton: CRC Press.

29. Melpolder, F. W., Brown, R. A., Washall, T. A., Doherty, W., \& Headington, C. E. (1956). Composition of lubricating oil use of newer separation and spectroscopic methods. Analytical Chemistry, 28(12), 1936-1945. http://dx.doi.org/10.1021/ ac60120a035.

30. Stanford, L. A., Kim, S., Rodgers, R. P., \& Marshall, A. G. (2006). Characterization of compositional changes in vacuum gas oil distillation cuts by electrospray ionization Fourier Transform-Ion Cyclotron Resonance (FT-ICR) mass spectrometry. Energy \& Fuels, 20(4), 1664-1673. http://dx.doi. org/10.1021/ef060104g.

31. Klavins, M., Porshnov, D., Ansone, L., Robalds, A., \& Dreijalte, L. (2012). Peat as natural and industrial sorbent. In R. A. R. Ramos, I. Straupe \& T. Panagopoulos (Eds.). Recent researches in environment, energy systems \& sustainability (pp. 146-151). Portugal: WSEAS Press.

Received: Nov. 09, 2015

Revised: Apr. 12, 2016

Accepted: May 16, 2016 